\title{
As Metáforas Primárias na Aquisição da LINGUAGEM: UM ESTUdO INTERLINGÜÍSTICO*
}

(Primary Metaphores in Language Acquisition an Interlinguistic Study)

\author{
Maity SiqueIRA \\ Regina Ritter LAMPRECHT \\ (Puc-RS)
}

\begin{abstract}
Situated within the framework of the Conceptual Metaphor Theory, this research focuses on the comprehension of primary metaphors, using a crosslinguisticdevelopmental perspective. Data come from interviews with monolingual Brazilian Portuguese and American English native speakers at the ages of 3 to 10, along with adult native speakers. The results obtained from two tasks (verbal and non-verbal) revealed that the comprehension of primary metaphors is an ability that emerges early in life and is linked to the kind of mapping involved in each conceptual metaphor. The comprehension of primary metaphors followed three stages both for the Brazilian and the American participants.
\end{abstract}

KEY-WORDS: primary metaphors; language acquisition; figurative language development; cognitive linguistics.

RESUMO: Este trabalho apresenta um estudo interlingüístico e evolutivo da compreensão de oito metáforas primárias sob a perspectiva da Teoria da Metáfora Conceitual. Os dados foram obtidos através de entrevistas com crianças de 3 a 10 anos de idade, monolingües, falantes nativas de português brasileiro ou de inglês norte-americano, bem como com adultos das mesmas comunidades lingü̈íticas. Os resultados de duas tarefas (verbal e não-verbal) aplicadas revelaram que a compreensão de metáforas primárias é uma habilidade que emerge cedo na infância e está relacionada ao tipo de mapeamento envolvido em cada metáfora conceitual. Tanto para os participantes brasileiros quanto para os participantes norte-americanos, a compreensão de metáforas primárias se deu em três estágios.

PALAVRAS-CHAVE: metáforas primárias; aquisição da linguagem; desenvolvimento da linguagem figurada; lingüística cognitiva.

* Esta pesquisa foi parte integrante da tese de Doutorado da primeira autora, apresentada no Programa de Pós-Graduação em Letras da PUCRS, sob a orientação da segunda autora, com financiamento da CAPES.

D.E.L.T.A., 23:2, 2007 (245-272) 


\section{Introdução}

O objetivo deste estudo é investigar a aquisição de metáforas primárias em crianças falantes nativas de português brasileiro e crianças falantes nativas de inglês americano. Mais especificamente, objetiva-se detectar similaridades e diferenças na compreensão de metáforas primárias nessas duas línguas e verificar o padrão evolutivo baseado na compreensão das oito metáforas pesquisadas.

As metáforas primárias, objeto deste estudo, resultam de interações entre particularidades dos aparatos físico e cognitivo humanos, com suas experiências subjetivas no mundo, independentemente de língua e cultura (Grady, 1997). Em nossas experiências diárias, existem algumas situações que se repetem mais freqüentemente e cujo significado é mais saliente, em função do modo como essas experiências estão relacionadas a nossos objetivos. Quando enfrentamos um ambiente desconhecido à noite, por exemplo, tipicamente sentimos um desconforto maior do que se estivéssemos no mesmo ambiente durante o dia, quando a claridade permite um maior campo de visão e uma sensação de maior controle da situação. É essa estreita correlação experiencial entre o domínio-fonte (por ex., ESCURIDÃO), que serve como a fonte de inferências, e o domínio-alvo (por ex., INSEGURANÇA), ao qual as inferências se aplicam, que vai propiciar o surgimento de uma metáfora primária (por ex., RUIM É ESCURO).

$\mathrm{Na}$ perspectiva da lingüística cognitiva, uma sentença metafórica é um fenômeno lingüístico que deriva de um mapeamento conceitual entre um domínio-fonte e um domínio-alvo. Conforme Kövecses (2005), podemos usar as expressões metafóricas para acessar tais mapeamentos, supondo que existem ligações entre determinados domínios conceituais - ligações essas que poderão ser empiricamente testadas através de experimentos como este.

Alguns autores (Gibbs, 1994; Steen e Gibbs, 1999; Semino et al., 2004) têm questionado a validade de uma pronta passagem de itens lingüísticos para a inferência de uma estrutura cognitiva ${ }^{1}$. Em termos de aquisição de metáforas, supomos que, se uma criança entende uma expres-

1 Semino et al. (2004) alertam para o fato de que ainda não dispomos de procedimentos explícitos e rigorosos para especificar metáforas conceituais a partir de metáforas lingüísticas encontradas nos dados. Esses autores postulam que análises lingüísticas que gerem resultados cognitivamente plausíveis podem ser a base de discussões acerca dessa questão. 
são metafórica, ela, de alguma forma, acessa o mapeamento conceitual subjacente. Isso não quer dizer que ela (ou mesmo um adulto) possa conscientemente indicar tal mapeamento, pois tais processos de pensamento, segundo Kövecses (2005), são amplamente inconscientes.

Não se conhecem pesquisas específicas que tratem da aquisição de metáforas primárias por crianças brasileiras. As evidências psicolingüísticas fornecidas neste trabalho, desse modo, podem constituir um avanço para a área da aquisição da competência da fala figurada.

Antes de apresentar nossa pesquisa, faremos um breve levantamento de evidências psicolingüísticas encontradas em estudos anteriores em relação às principais variáveis investigadas neste estudo: idade, língua, tipo de tarefa e tipo de sentença. Embora o enfoque desta pesquisa seja a compreensão de metáforas, parte das evidências apresentadas refere-se à produção de metáforas, uma vez que essas duas habilidades - distintas, mas interligadas - fazem parte da capacidade para a linguagem figurada ${ }^{2}$ (Gibbs, 1994).

\section{Evidências psicolingüísticas}

A idade tem sido a variável mais amplamente testada nas pesquisas que analisam a competência para compreensão ou produção da linguagem figurada. Os resultados encontrados são diversos e, por vezes, contraditórios. As principais causas da obtenção de resultados discrepantes são as diversidades metodológicas e teóricas em que esses estudos se baseiam. Entretanto, existem algumas condições específicas e observa-se uma certa ordem na aquisição das metáforas.

Algumas pesquisas recentes (Ozçaliskan, 2002; Pearson, 1990; Siqueira, 2001; Siqueira e Settineri, 2003) demonstram que mesmo crianças novas são capazes de perceber similaridades entre domínios diversos, desde que os domínios comparados lhes sejam familiares (Billow, 1981; Elbers, 1988; Gardner, 1974; Laganaro, 1997; Moore, 1988; Vosniadou, 1987).

2 O capítulo 9 (The poetic minds of children) da obra 'The poetics of mind' (Gibbs, 1994) é dedicado às evidências da psicologia do desenvolvimento e da psicolingüística para a habilidade de compreender e utilizar a linguagem figurada. Uma lista dos achados relativos às variáveis idade, tipo de tarefa, meio de elicitação, contexto e complexidade da forma lingüística na aquisição das metáforas é fornecida por Ozçaliskan (2002). 
Cameron (1997) afirma que a maior exigência no processamento das metáforas reside na necessidade de acessar e selecionar informações relevantes sobre os domínios fonte e alvo, além de encontrar elos de ligação que resolvam a incongruência entre tais domínios. Para outros autores, a percepção de similaridades é condição necessária, mas não suficiente, para que um enunciado infantil seja classificado como metafórico.

Marschark e Nall (1985) e Gibbs (1996) enfatizam que a intenção de violar categorias semânticas estabelecidas é uma condição necessária para que se considere uma produção infantil como metafórica. Marschark e Nall supõem que é necessário que se acesse a intenção da criança, a fim de distinguir produções com sentido aparentemente figurado daquelas com sentido realmente figurado. Contudo, definir se uma criança pequena, ao proferir um enunciado, tem ou não a intenção de torná-lo metafórico, não é uma tarefa fácil.

A questão da intenção pode ser vista por diferentes aspectos. A intenção a que Gibbs (1996) se refere está relacionada à capacidade de reconhecimento, por parte da criança, de que existem similaridades não-literais entre dois eventos ou objetos comparados. A idéia, nesse caso, é evitar que qualquer ocorrência lingüística que revele a percepção de alguma similaridade seja confundida com expressões metafóricas. Já para Marschark e Nall (1985), a intenção parece estar mais ligada à motivação consciente de produzir um enunciado metafórico. Sob o ponto de vista de Johnson (1999), o que interessa é saber se a criança tem ou não condições cognitivas de diferenciar os dois sentidos possíveis - literal ou figurado - de uma mesma palavra.

Conforme a Teoria da Conflação, proposta por Johnson (1999), o desenvolvimento lingüístico e conceitual infantil consiste parcialmente em aprender a distinguir os sentidos literal e metafórico. Johnson analisou os significados do verbo 'ver' em um corpus lingüístico, e argumentou contra a idéia de que as crianças aprendem primeiro o sentido estritamente literal, visual, e só posteriormente associam essa mesma forma 'ver' com o sentido metafórico de 'entender', de 'se dar conta', através de um mapeamento metafórico do tipo ENTENDER É VER. Analisando as interações de uma criança com adultos, ele percebeu que em várias expressões (por ex., "vamos ver o que tem dentro desta caixa") proferidas por um adulto, o significado de 'ver' poderia tanto se referir a um evento visual como a um evento 
mental. A conflação, segundo o autor, caracteriza um estágio em que os componentes do significado, que podem ser expressos diferenciadamente pelos adultos em diferentes contextos, são expressos indiferenciadamente em diversos contextos pelas crianças. O estágio seguinte ao da conflação na aquisição de palavras polissêmicas, que leva ao surgimento da metáfora conceitual, é o da diferenciação.

Conforme as análises longitudinais feitas por Johnson, por volta do terceiro ano de vida, as crianças começam a proferir enunciados em que se observam sobreposições de sentido (literal e metafórico) e, por volta do quarto ano de vida, elas começam a produzir diferentes enunciados com a mesma palavra, os quais, de acordo com o contexto da enunciação, podem ser considerados literais ou metafóricos.

Outra questão relacionada à questão da intenção é a da motivação infantil para a produção de metáforas. Para dar conta do motivo que leva uma criança a produzir uma metáfora, Ortony (1975) formula a tese da inacessibilidade, referente às dificuldades inerentes à definição de alguns conceitos e a lacunas no vocabulário infantil.

Poderia-se pensar que os falantes sentem-se compelidos a recorrer a inovações lingüísticas em função de uma deficiência sintática ou lexical. Porém, não é só por uma questão de falta ou deficiência da língua que as crianças produzem metáforas; eventualmente tal produção pode se dar por simples preferência da criança (Elbers, 1988).

Siqueira (2001) observou que crianças de 3 a 6 anos de idade já utilizam uma grande variedade de vocábulos para expressar um mesmo tipo de sentimento, o que suscita alguns questionamentos a respeito da tese da inacessibilidade. Em primeiro lugar, será que sentimentos, como raiva ou felicidade, são conceitos difíceis de serem definidos? Ou ainda, o quê, exatamente, caracteriza um conceito inerentemente difícil de ser definido? Os sujeitos que participaram da pesquisa de Siqueira já manifestam verbalmente tais emoções. As verbalizações dos sujeitos, em resposta a uma figura representando pessoas felizes, foram "alegres", "se sentindo bem", "tri feliz", "se divertindo", enquanto as verbalizações feitas em resposta a uma figura representando uma briga incluíram "brabo", "com muita raiva”, "com egos ofendidos", "furiosos". Se as crianças em idade pré-escolar conseguem expressar com várias palavras um mesmo sentimento, é porque seu vocabulário não é tão restrito a ponto de não poder expressar literalmente esse sentimento. 
De acordo com a Teoria Conceitual da Metáfora (Lakoff e Johnson, 1980), falar metaforicamente é uma decorrência natural do fato de que as pessoas pensam metaforicamente. As metáforas conceituais, por sua vez, são motivadas e baseadas na experiência corporal - como o corpo humano funciona e interage com o mundo físico (Yu, 1998).

Quanto à variável 'idade', a expectativa nesta pesquisa é a de que as crianças demonstrem uma melhor compreensão em todos os domínios conceituais com o aumento da idade, em função de uma evolução geral no desenvolvimento das capacidades cognitivas. Em sintonia com trabalhos recentes, espera-se que mesmo as crianças mais novas, entre 3 e 4 anos de idade, demonstrem uma habilidade de compreensão das metáforas (Ozçaliskan, 2002; Siqueira, 2001; Siqueira e Settineri, 2003).

Além da idade, outra variável freqüentemente abordada na literatura relativa à aquisição da fala figurada é o tipo de sentença: literal ou metafórica. Pearson (1990) manipulou essa variável, comparando a compreensão de expressões metafóricas, literais e sem sentido (nonsense), e concluiu que as crianças em idade pré-escolar são sensíveis às metáforas e processam as figuras de linguagem paralelamente aos aspectos literais.

A variável 'tipo de sentença' foi incluída nesta pesquisa para que se pudesse verificar, através de sentenças literais e metafóricas, o nível de entendimento das crianças quanto aos conceitos utilizados como alvo das metáforas. A expectativa é a de que mesmo os sujeitos mais novos (de 3 a 4 anos de idade) tenham um desempenho acima do nível do acaso tanto na compreensão literal quanto na compreensão metafórica, uma vez que os domínios arrolados fazem parte da sua experiência diária.

Quanto à variável 'língua', com exceção dos estudos feitos em italiano (Cacciari e Tabossi, 1988; Levorato, 1993; Caramelli e Montanari, 1995; Levorato e Cacciari, 1995), a maioria das pesquisas utiliza crianças falantes de inglês como sua população alvo, o que diminui a possibilidade de generalização dos resultados.

Somente um estudo interlingüístico que engloba a língua portuguesa na produção infantil de metáforas é conhecido (Dowker et al., 1998). Esse estudo investigou a produção de metáforas por crianças brasileiras, inglesas, italianas, polonesas e francesas. Os resultados da pesquisa de Dowker et al. apontam para diferenças quantitativas na produção de símiles - consi- 
deradas produções metafóricas pelos autores - nos poemas de crianças das nacionalidades supracitadas, mas não fornecem explicações para esse fato. Tal pesquisa não contribui para o esclarecimento das semelhanças ou diferenças entre a compreensão de metáforas primárias por dois motivos. Primeiro, porque a pesquisa de Dowker et al. leva em consideração a produção de símiles, um fenômeno diferente daquele que nos interessa. Segundo, porque a análise de Dowker e colaboradores não contempla aspectos qualitativos dos dados de produção, essenciais para qualquer análise mais esclarecedora sobre as diferenças entre línguas ou culturas.

Apesar de não incluir sujeitos brasileiros, a tese de Ozçaliskan (2002) é mais relevante para o presente estudo. Ozçaliskan investigou o entendimento de metáforas primárias por crianças turcas e norte-americanas de 3 , 4 e 5 anos de idade. O padrão de desenvolvimento encontrado por ela obedece as seguintes etapas: aos 4 anos de idade, as crianças compreendem metáforas contextualizadas; aos 5 anos, elas são capazes de compreender mapeamentos metafóricos apresentados fora de contexto. Suas análises indicam que não há um efeito principal da língua falada pelos sujeitos na compreensão de metáforas primárias.

Em relação às duas línguas pesquisadas (Português Brasileiro e Inglês Americano), espera-se que a língua falada pela criança não afete a compreensão das metáforas primárias, já que a experiência com os domínios-fonte pesquisados, em princípio, pouco depende da língua falada ou da cultura em que as metáforas são produzidas. Os domínios-fonte escolhidos para este estudo (altura, temperatura, claridade, proximidade, maciez, tamanho, peso e deglutição) fazem parte da experiência sensório-motora diária das crianças. Espera-se que esses domínios, estruturados conceitualmente a partir de experiências básicas, facilitem o entendimento infantil dos domínios-alvo, de natureza mais abstrata (felicidade, intensidade de emoções, bondade, intimidade emocional, aceitação, dificuldade, importância e simpatia), e conduzam a uma compreensão das metáforas em uma tenra idade.

A variável 'língua', de fato, está imbricada em um tópico central da Teoria das Metáforas Primárias, o da universalidade. Já foi sugerido aqui que as metáforas primárias são fenômenos de natureza lingüística, conceitual e corpórea. Uma vez que a formação de conceitos via mapeamentos metafóricos primários é restringida por aspectos corpóreos, em princípio 
independentes de cultura ${ }^{3}$, espera-se que aspectos lingüísticos mais dependentes de cultura sejam minimizados nesse tipo de metáfora.

Quanto à variável 'tipo de tarefa', alguns estudos chegaram a resultados contraditórios. Segundo Winner et al. (1979), a compreensão infantil de metáforas melhora se o instrumento utilizar apresentações verbais acrescidas de pictóricas. Já para Billow (1975), a compreensão infantil não é influenciada pelo fato de as metáforas serem apresentadas somente de forma verbal ou de a apresentação verbal ser acrescida de figuras.

Pesquisas posteriores (Dent, 1987; Epstein e Gamblin, 1994) revelam que existe um efeito facilitador da apresentação pictórica em relação à apresentação verbal das metáforas. A conclusão a que Epstein e Gamblin chegaram é a de que crianças em idade pré-escolar são melhores tanto no reconhecimento quanto na explicação de metáforas pictóricas, em relação às metáforas apresentadas verbalmente.

Um fator que não foi levado em conta pelos estudos apresentados, mas que pode influenciar os resultados, particularmente em tarefas verbais, é o da convencionalidade. De acordo com Lakoff e Turner (1989), as metáforas são convencionais quando estão estabelecidas em nossa experiência diária, sendo utilizadas automaticamente e sem esforço. Kövecses (2002) reitera a posição de Lakoff e Turner a respeito da convencionalidade de uma metáfora, pois postula que tanto as metáforas lingüísticas quanto as conceituais são convencionais quando estão fortemente estabelecidas em uma comunidade lingüística. Segundo ele, enquanto uma metáfora conceitual convencional é uma forma estabelecida de entender um domínio abstrato, uma metáfora lingüística convencional é uma forma estabelecida de falar sobre um domínio abstrato.

Nossa expectativa é a de que a variável 'tipo de tarefa' influencie o desempenho das crianças com relação à compreensão de metáforas. Além disso, espera-se que um padrão evolutivo seja observado na compreensão das diversas metáforas primárias, tanto na tarefa verbal quanto na tarefa não-verbal.

\footnotetext{
3 A questão da universalidade e da influência cultural na compreensão e produção de metáforas é amplamente discutida no livro 'Metaphor in Culture: universality and variation', de Zoltán Kövecses (2005). Kövecses postula que as metáforas são fenômenos de natureza não só lingüística e conceitual, mas também sociocultural, neural e corpórea.
} 
Considerando a Teoria da Metáfora Primária e os estudos e evidências apresentados, os dados resultantes da pesquisa empírica descrita neste trabalho foram analisados a partir das seguintes hipóteses:

a) Não existem diferenças significativas na compreensão infantil de metáforas primárias na língua inglesa e na língua portuguesa, dado que, por definição, as metáforas primárias independem de cultura ou língua falada.

b) Existe um padrão evolutivo na compreensão das diversas metáforas primárias, e esse padrão é mais evidente na tarefa verbal do que na tarefa não-verbal, uma vez que a tarefa não-verbal depende de um amadurecimento cognitivo geral, e a tarefa verbal, além do amadurecimento cognitivo, requer o conhecimento de um sistema lingüístico específico.

\section{Experimento}

\section{Método}

Sujeitos

Oitenta e seis crianças brasileiras monolíngües falantes de português e oitenta e quatro crianças norte-americanas monolíngües falantes de inglês, com idades entre 3 e 10 anos participaram da pesquisa. Um grupo de 20 adultos em cada uma das línguas também fez parte da amostra.

Os dados do português e do inglês foram coletados respectivamente nas cidades de Porto Alegre, RS (Brasil) e de Santa Cruz, CA (Estados Unidos). As crianças freqüentavam pré-escolas e escolas particulares. $\mathrm{O}$ grupo de adultos que participou da pesquisa foi composto por estudantes da University of California, Santa Cruz (UCSC) e da Pontifícia Universidade Católica do Rio Grande do Sul (PUCRS).

\section{Delineamento}

O estudo envolveu um delineamento misto $(5 \times 2 \times 2 \times 2)$.

A primeira variável independente refere-se à idade dos sujeitos, divididos em cinco faixas etárias (3-4, 5-6, 7-8, 9-10 anos e adultos), e a segunda 
variável independente refere-se à língua falada pelos sujeitos, português ou inglês. A terceira variável é o tipo de sentença apresentado: metáfora primária ou alvo literal. A quarta variável refere-se ao tipo de tarefa: verbal ou não-verbal.

As variáveis dependentes foram as respostas dos sujeitos, que representavam duas respostas para perguntas equivalentes no instrumento de compreensão verbal, e uma escolha forçada e a justificativa para tal escolha no instrumento de compreensão não-verbal.

\section{Material}

Dois instrumentos foram desenvolvidos para a pesquisa, sendo o primeiro constituído por uma tarefa verbal e o segundo por uma tarefa nãoverbal. Na tarefa verbal, foi desenvolvida uma versão para a língua portuguesa e outra para a língua inglesa. As duas versões foram elaboradas concomitantemente, e tentou-se manter, sempre que possível, um paralelismo entre elas, considerando a estrutura gramatical das línguas e fatores pragmáticos. Na tarefa não-verbal, as perguntas foram adaptadas para cada uma das línguas, mantendo-se idênticas as figuras apresentadas aos sujeitos. Os instrumentos foram avaliados por três juízes norte-americanos e três juízes brasileiros.

\section{Compreensão verbal}

O instrumento de compreensão verbal foi elaborado a partir de oito metáforas primárias selecionadas da tese de Grady (1997), apresentadas abaixo:

MP1. A FELICIDADE É PARA CIMA (HAPPINESS IS UP); MP2. INTENSIDADE DE EMOÇÃO É CALOR (INTENSITY OF EMOTION IS HEAT);

MP3. BOM É CLARO/ RUIM É ESCURO (GOOD IS BRIGHT/ BAD IS DARK); MP4. DIFICULDADE É PESO (DIFFICULTY IS HEAVINESS); MP5. ACEITAR É ENGOLIR (ACQUIESCING IS SWALLOWING); MP6. INTIMIDADE EMOCIONAL É PROXIMIDADE (EMOTIONAL INTIMACY IS PROXIMITY);

MP7. IMPORTÂNCIA É TAMANHO (IMPORTANCE IS SIZE); MP8. SIMPATIA/COMPAIXÃO É SUAVIDADE (SYMPATHY IS SOFTNESS). 
Para cada uma das oito metáforas conceituais foram construídas duas sentenças (Anexo I). A primeira sentença representa uma instanciação lingüística da metáfora conceitual primária (doravante MP); a segunda sentença é uma utilização literal do alvo, paráfrase da metáfora primária (doravante $\mathrm{AL}$ ). Ou seja, a sentença metafórica e a sentença literal expressam a mesma idéia. Após cada uma das sentenças foram apresentadas questões idênticas aos sujeitos. O mesmo sujeito só escutava uma sentença gerada a partir de uma metáfora conceitual, MP ou AL. Na MP1, A FELICIDADE É PARA CIMA, por exemplo, o domínio-alvo é FELICIDADE, manipulado de modo a ser apresentado de forma figurada na sentença MP e literalmente na sentença $\mathrm{AL}$, demonstrado a seguir:

MP- 'A Lúcia está se sentindo para cima depois de encontrar o Tom'.

AL- 'A Lúcia está feliz depois de encontrar o Tom'.

Tanto os sujeitos que escutavam a MP quanto os sujeitos que escutavam a AL respondiam às seguintes perguntas:

'Como será que a Lúcia está se sentindo?'

'Será que o Tom deu boas ou más notícias para ela?'

\section{Compreensão não-verbal}

A fim de verificar se as crianças entendem conceitos abstratos em termos de conceitos mais concretos, independentemente da expressão metafórica lingüística correspondente, oito figuras foram criadas para representar as metáforas primárias utilizadas no primeiro instrumento. A tarefa consiste em olhar e/ ou tocar os bonecos - apelidados de Duni-apresentados, escolhendo uma das duas possibilidades.

Na MP1, era apresentado um Duni mais embaixo e outro no alto da folha; na MP2, eram utilizados dois sacos de gel em que a única diferença era o fato de que um dos sacos era aquecido e o outro resfriado; na MP3, era apresentado um Duni verde escuro e outro verde claro; na MP4, um Duni estava carregando um objeto mais pesado do que o outro; na MP5, um Duni estava comendo um sorvete, e o outro estava segurando um sorvete; na MP6, eram apresentados dois Dunis próximos e dois distantes; na MP7 era apresentado um Duni grande e outro pequeno; e na MP8 um Duni era forrado de lixa e outro de veludo.

Após as crianças darem as suas respostas, elas eram estimuladas a justificar suas opções. Ou seja, após a criança ter dado a sua resposta sobre 
qual era o Duni mais feliz, por exemplo, a pesquisadora perguntava por que a criança achava que o boneco que está em cima é o mais feliz, ou por que ela achava que o boneco que está para baixo é o mais feliz.

\section{Procedimento}

A aplicação dos instrumentos de pesquisa foi feita pela primeira autora. As entrevistas foram individuais, nas escolas das crianças. Na tarefa verbal, a criança ouvia uma fita gravada por uma falante nativa da sua língua e respondia imediatamente após ter escutado cada sentença. $\mathrm{Na}$ tarefa não-verbal, a pesquisadora mostrava a figura, lia o enunciado e perguntava por que aquele era o Duni escolhido. Não havia restrição de tempo para a resposta da criança.

\section{Análise dos resultados}

\section{Análise quantitativa}

A compreensão das metáforas foi avaliada através do desempenho dos sujeitos nas tarefas verbal e não-verbal. Para a tarefa não-verbal, atribuiuse 1 ponto para cada resposta esperada. Os sujeitos poderiam obter um escore de 0,1 ou 2 pontos para cada sentença metafórica ou literal na tarefa verbal, uma vez que a cada um desses tipos de sentença seguiam-se duas perguntas.

$\mathrm{Na}$ tarefa não-verbal, os sujeitos receberam uma pontuação de 1 (resposta esperada) ou 0 (outras respostas ou falta de resposta) nas questões de escolha forçada. Para as justificativas dadas quanto à escolha forçada, as respostas dos sujeitos foram pontuadas com 1 (justificativa esperada) ou 0 (outras justificativas ou falta de justificativa). Um ponto foi computado sempre que o sujeito especificava as razões físicas compatíveis com a metáfora em questão (Duni acima, Duni quente, Duni claro, Dunis próximos, Duni engolindo o sorvete, Duni curvado, Duni maior e Duni aveludado). Os sujeitos poderiam obter um escore máximo de 2 pontos em cada tarefa.

Os resultados foram verificados através de análises de variância (ANOVA). Foi considerado um nível de significância de 0,05 em todas as análises estatísticas. 
Uma estatística descritiva geral é apresentada a seguir (Quadro 1).

Quadro 1: Estatística descritiva geral

\begin{tabular}{|l|c|c|c|c|c|}
\hline Variável & Rótulo & Descrição & Sujeitos (N) & Média & Desvio padrão \\
\hline Tipo de & MP & Metáfora primária & 210 & 1,53 & $(0,59)$ \\
sentença & AL & Alvo & 210 & 1,64 & $(0,52)$ \\
\hline Língua & PB & Português & 106 & 1,61 & $(0,38)$ \\
& IA & Inglês & 104 & 1,56 & $(0,38)$ \\
\hline Idade & 1 & 3 a 4 anos & 41 & 0,99 & $(0,33)$ \\
& 2 & 5 a 6 anos & 44 & 1,48 & $(0,30)$ \\
& 3 & 7 a 8 anos & 41 & 1,72 & $(0,21)$ \\
& 4 & 9 a 10 anos & 44 & 1,86 & $(0,67)$ \\
& 5 & Adultos & 40 & 1,88 & $(0,17)$ \\
\hline Tarefa & $\mathrm{V}$ & Verbal & 210 & 1,53 & $(0,59)$ \\
& $\mathrm{NV}$ & Não-verbal & 210 & 1,52 & $(0,38)$ \\
\hline
\end{tabular}

Análises de variância (ANOVA) mostraram um efeito significativo ( $\mathrm{F}$ $(4,170)=72,415, \mathrm{p}<0,01)$ da idade na compreensão das sentenças apresentadas, com aumentos na idade levando a uma melhor compreensão semântica.

Uma análise de medidas repetidas de variância (ANOVA), com 'tipo de tarefa' como fator intra-sujeitos e 'idade' como fator intersujeitos, demonstrou que o desempenho dos sujeitos nas duas tarefas foi fortemente influenciado pelo fator idade $(\mathrm{F}(4,205)=50,723, \mathrm{p}<0,01)$. Também foi observada uma interação significativa entre o tipo de tarefa realizada e a idade do sujeito, com $\mathrm{p}<0,01$. Isto é, sujeitos de diferentes faixas etárias alternaram melhores desempenhos nas duas tarefas, conforme mostra o Gráfico 1. 


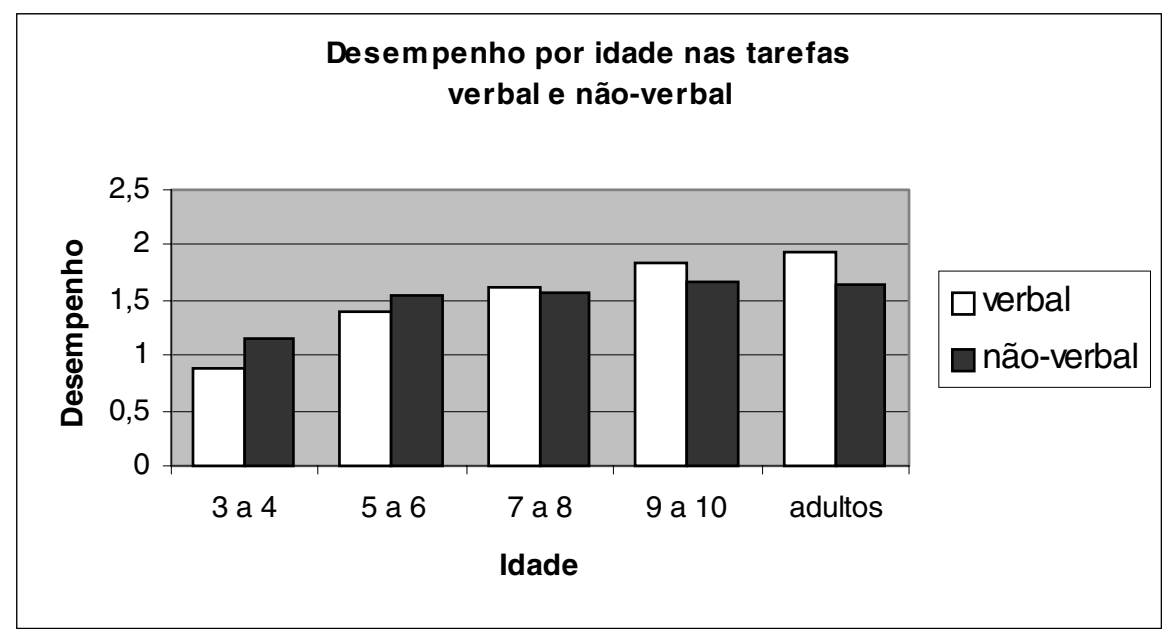

Gráfico 1: Médias nas tarefas verbal e não-verbal, por idade

Os resultados obtidos indicam que aos 7 anos de idade a criança já adquiriu a competência para a compreensão das metáforas, uma vez que a partir dessa idade já não se encontram resultados significativamente diferentes daqueles apresentados pelos adultos.

O conhecimento da língua parece influenciar a compreensão de metáforas primárias nas diferentes faixas etárias. As médias obtidas pelas crianças de 3 a 4 anos nas tarefas não-verbal e verbal sugerem que essas crianças entendem alguns conceitos que conectam metaforicamente um domínio mais abstrato a um domínio mais concreto, ainda que desconheçam muitas das expressões lingüísticas correspondentes. As crianças mais velhas, por outro lado, já têm tal conhecimento das expressões lingüísticas da sua língua materna que seu desempenho na tarefa verbal supera o seu desempenho na tarefa não-verbal, assim como os adultos. Na tarefa não-verbal, que depende menos da compreensão de uma língua específica, a diferença entre idades não é tão marcante.

A comparação, obtida através de um Teste T, entre as tarefas - verbal e não-verbal - não aponta para um efeito significativo do tipo de instrumento empregado para verificar a compreensão de metáforas primárias, $\operatorname{com} \mathrm{t}(209)=0,389, \mathrm{p}>0,05$. 
Os resultados relativos ao desempenho de acordo com as variáveis 'idade' e 'tipo de tarefa', nas oito metáforas primárias estudadas, estão expressos na Tabela I.

Tabela I: Desempenho (médias) por idade e tarefa em cada metáfora primária

\begin{tabular}{l|c|cccccccc}
\hline Idade & Tarefa & MP1 & MP2 & MP3 & MP4 & MP5 & MP6 & MP7 & MP8 \\
& & & & & & & & & \\
\hline \multirow{2}{*}{ 3-4 anos } & verbal & 1,1 & 1,2 & 1,0 & 0,3 & 0,64 & 1,6 & 0,5 & 0,7 \\
& não-verbal & 0,91 & 1,3 & 0,9 & 1,0 & 0,82 & 1,2 & 1,3 & 1,6 \\
5-6 anos & verbal & 1,0 & 1,0 & 1,91 & 0,54 & 1,42 & 2,0 & 1,73 & 1,73 \\
& não-verbal & 1,0 & 1,7 & 1,18 & 1,64 & 0,67 & 1,8 & 1,27 & 1,64 \\
7-8 anos & verbal não- & 0,82 & 1,9 & 2,0 & 1,0 & 1,73 & 2,0 & 1,8 & 1,7 \\
& verbal & 1,36 & 1,4 & 1,7 & 1,7 & 0,73 & 2,0 & 0,9 & 2,0 \\
9-10 anos & verbal & 1,27 & 2,0 & 2,0 & 1,6 & 1,73 & 2,0 & 2,0 & 2,0 \\
& não-verbal & 1,36 & 1,5 & 1,85 & 1,7 & 1,27 & 2,0 & 1,54 & 1,7 \\
adultos & verbal & 2,0 & 2,0 & 1,9 & 1,9 & 1,8 & 1,9 & 2,0 & 2,0 \\
& não-verbal & 1,8 & 1,4 & 1,5 & 1,4 & 0,6 & 2,0 & 0,9 & 1,8 \\
\hline
\end{tabular}

Os resultados expressos na Tabela I apontam para a idéia de que há um padrão geral de desenvolvimento na compreensão de metáforas primárias, que pode ser demonstrado através da tarefa verbal e da tarefa nãoverbal. No entanto, considerando o desempenho dos sujeitos mais novos (3-4 e 5-6 anos) como parâmetro de prontidão para a compreensão de cada metáfora primária, percebe-se que essa prontidão não se dá na mesma ordem nas tarefas verbal e não-verbal.

Uma variável que pode ter influenciado os resultados obtidos na tarefa verbal é a convencionalidade das expressões utilizadas. Embora essa variável não tenha sido controlada, é possível supor que, ao menos em alguns casos, o desempenho na tarefa verbal tenha sido influenciado pelo grau de convencionalidade das expressões lingüísticas utilizadas no instrumento verbal. Não houve um efeito principal de língua na compreensão de metáforas primárias e sentenças literais, $\operatorname{com} \mathrm{F}(1,208)=0,332, \mathrm{p}>0,05$, conforme evidenciado pela análise de variância. Também não houve interação significativa $(\mathrm{p}>0,05)$ entre o tipo de sentença apresentada e a língua dos sujeitos. Isto é, sujeitos brasileiros e americanos tiveram o mesmo padrão de compreensão de MPs e ALs.

Uma análise de medidas repetidas de variância (ANOVA) cruzando língua e idade como fator inter-sujeitos e tipo de sentença como fator in- 
tra-sujeitos apontou um efeito principal do tipo de sentença $(\mathrm{p}<0,05)$ e um efeito principal da idade, $\operatorname{com} \mathrm{F}(4,200)=59,961, \mathrm{p}<0,01)$. Não foi verificado um efeito principal de língua $(\mathrm{F}(1,200)=1,602, \mathrm{p}>0,05)$, nem interações entre língua e idade $(\mathrm{p}>0,05)$ ou entre língua e tipo de sentença $(p>0,05)$. A não verificação de um efeito principal da variável língua, combinada com a ausência de interação entre língua e idade - e com uma correlação positiva entre idade e média de acertos nas duas línguas - reforça a idéia de que há um caráter evolutivo universal na compreensão dos conceitos pesquisados.

$\mathrm{Na}$ tarefa não-verbal, foram feitas duas análises levando em conta as variáveis 'idade' e 'língua'. A primeira engloba as respostas dos sujeitos para as questões de escolha forçada e a justificativa para tal escolha em cada metáfora primária, e a segunda considera somente as respostas de escolha forçada.

Considerando as duas respostas - de escolha forçada e a justificativa para tal escolha - os resultados apontam tanto para um efeito principal de língua $(\mathrm{F}(8,193)=3,484, \mathrm{p}<0,001)$ quanto para um efeito principal de idade $(\mathrm{F}(32,784)=4,260, \mathrm{p}<0,01)$. O efeito principal de idade é esperado e corrobora a hipótese de que há um fator de desenvolvimento em jogo na compreensão de metáforas primárias. O efeito da língua na compreensão de metáforas primárias, por sua vez, contraria as expectativas, uma vez que, por hipótese, as metáforas primárias independem da cultura em que o sujeito está inserido, particularmente se tal compreensão for medida através de uma tarefa não-verbal.

A segunda análise revelou resultados semelhantes aos da primeira análise. Nesse caso, também houve um efeito significativo das variáveis idade e língua, com $\mathrm{F}(32,784)=2,348, \mathrm{p}<0,05$ na variável idade e $\mathrm{F}(32,193)=$ 2,301, $\mathrm{p}<0,01$ na variável língua.

Se consideradas as variáveis idade e língua em conjunto, não houve interação estatisticamente significativa em nenhuma das metáforas. Isto é, os escores dos sujeitos brasileiros e americanos foram compatíveis em todas as idades na questão de escolha forçada da tarefa não-verbal. A diferença entre idades diminuiu quando a justificativa dos sujeitos, que constitui uma meta-habilidade, foi desconsiderada. 
Quanto à variável língua, quando consideradas somente as respostas dos sujeitos, sem a justificativa para tais respostas, só houve diferença significativa na metáfora primária A FELICIDADE É PARA CIMA, com $\mathrm{F}(1,200)=8,263, \mathrm{p}<0,01$. Constata-se que a diferença entre as línguas também diminui quando a justificativa dos sujeitos é desconsiderada.

Esses resultados indicam que, ainda que na grande maioria das metáforas primárias analisadas não tenha sido verificado um efeito principal da língua falada pelos sujeitos, deve se considerar a possibilidade de que fatores culturais influenciem a conceitualização de determinadas metáforas primárias.

Uma análise de medidas repetidas de variância (ANOVA), cruzando língua como fator intersujeitos e tipo de sentença como fator intra-sujeitos, apontou um efeito principal para o tipo de sentença $(\mathrm{F}(2,207)=3,543$, $\mathrm{p}<0,05)$. Não foi verificado um efeito principal de língua $(\mathrm{F}(1,208)=0,947$, $\mathrm{p}>0,05)$, nem uma interação $(\mathrm{F}(2,207)=1,947, \mathrm{p}>0,05)$ entre língua e tipo de sentença, o que indica que o padrão de compreensão de metáforas primárias e sentenças literais apresentado pelos informantes independe da língua que eles falam (portuguesa ou inglesa) ou da comunidade lingüística a que pertencem (brasileira ou norte-americana).

\section{Análise qualitativa e discussão dos resultados}

A análise qualitativa baseia-se nas respostas obtidas através da tarefa não-verbal, já que essa inclui uma pergunta aberta sobre cada metáfora primária, a qual propiciou uma maior riqueza nas respostas dos informantes. As declarações de participantes norte-americanos foram mantidas em inglês.

\section{Metáfora primária 1: A FELICIDADE É PARA CIMA}

$\mathrm{Na} \mathrm{MP} 1$, as justificativas dos participantes que acertaram a questão foram iguais nas duas línguas. Foram freqüentes respostas que justificavam a escolha em função da posição espacial ou do movimento ascendente do boneco, como ilustram os exemplos a seguir. 
(sujeito 23, 10 anos de idade) "He is jumping up. Sometimes when I'm happy I jump up in the air".

(sujeito 156, 8 anos) "Porque quando a gente tá feliz, a gente pula de alegria".

Os sujeitos 23 e 156 mencionam a correlação experienciada entre o sentimento de felicidade e o ato físico de pular. Percebe-se que a estreita correlação experiencial entre o domínio-fonte PARA CIMA e o domínioalvo FELICIDADE propicia o surgimento da metáfora primária A FELICIDADE É PARA CIMA.

\section{Metáfora primária 2: INTENSIDADE DE EMOÇÃO É CALOR}

$\mathrm{Na}$ MP2, o sujeito era convidado a escolher, entre um Duni quente e outro frio, qual o boneco apresentava emoções mais fortes. A maioria dos sujeitos que escolheu o boneco quente justificou sua escolha em função do calor, como ilustram os exemplos abaixo.

(sujeito 6, 5 anos) "Because it is hot. Strong feelings means hot".

(sujeito 16, 8 anos) "The hotter he is, the stronger the feeling he has".

(sujeito 189, adulto) "O quente passa mais sensações. O frio te amortece".

As respostas desses sujeitos revelam o estabelecimento de uma relação geral entre calor e intensidade de emoção, sem especificar o tipo de sentimento envolvido. Já outros sujeitos ligaram o calor a determinados sentimentos.

(sujeito 58, 5 anos) "Do you know Tinker Bell? She got mad and hot!" .

(sujeito 65, 9 anos) "Sometimes I say that someone is as cold as ice, it means he doesn't care about others. If you are warm you have good feelings, now I know why".

(sujeito 82, adulto) "It's got energy, it's hot. Reminds me of passion".

Embora a emoção possa tanto ser negativa (raiva, loucura) quanto positiva (paixão), a correlação experienciada entre a temperatura corporal e os momentos de fortes emoções motiva a metáfora conceitual INTENSIDADE DE EMOÇÃO É CALOR.

\section{Metáfora primária 3: BOM É CLARO}

$\mathrm{Na} \mathrm{MP} 3$, alguns adultos deram respostas "politicamente corretas", relacionadas à questão do racismo. Crianças de todas as idades, ao contrá- 
rio, deram respostas diretas, sem se importar com a questão do racismo, como mostram os exemplos abaixo.

(sujeito 62, 7 anos) "It's the lighter. Darker is always the bad guy".

(sujeito 143, 10 anos) "Para mim, quando a pessoa é escura, ela guarda coisas ruins, tá com a mente pesada".

(sujeito 81, adulto) "People refer to light as being good, dark as being bad, misterious".

O objetivo aqui não é julgar os informantes, mas tentar captar a motivação para a ocorrência das metáforas conceituais pesquisadas.

O sujeito 81 sugere que o escuro é ruim, misterioso. Isso, de alguma forma, remete à falta de precisão visual que ambientes escuros ocasionam. $\mathrm{O}$ escuro pode estar relacionado ao misterioso porque as pessoas não têm o mesmo domínio visual em ambientes escuros, em relação aos ambientes mais claros. Quanto mais claro é o campo visual, mais explícito se torna seu conteúdo. Provavelmente, a fusão do sentido 'visão' com a sensação psicológica de controle da situação gera a metáfora conceitual BOM É CLARO. A declaração a seguir, de uma criança, explicita o argumento de que o melhor é aquele que podemos controlar visualmente, que podemos ver melhor.

(sujeito 108, 6 anos) "Esse é o melhor porque ele é mais claro, dá para ver melhor a cara dele".

Outra possível motivação para a MP3 está relacionada às questões sanitárias. O que é visivelmente mais limpo, conseqüentemente mais claro, é conceituado como mais saudável, melhor, conforme a seguinte declaração.

(sujeito 144, 10 anos) "Porque ele é mais claro, mais limpo. Ele tem a ficha limpa".

O sujeito 144 não só fornece a motivação para a ligação metafórica entre claro e bom, como atualiza essa conexão, através de uma metáfora lingüística: "ele tem a ficha limpa". Se ele tem a ficha limpa, não constam coisas ruins, sujas, no seu currículo; logo, ele é uma boa pessoa.

\section{Metáfora primária 4: DIFICULDADE É PESO}

Os sujeitos que deram respostas esperadas na MP4 justificaram sua escolha pelo Duni com as pernas dobradas em função do provável peso do 
objeto que ele estava carregando. A única diferença entre os dois bonecos apresentados é o corpo (mais curvado) do boneco. Os sujeitos, por já terem observado situações em que o corpo de uma pessoa se curva sob o peso de uma carga, inferiram que uma caixa é mais pesada do que a outra. As respostas abaixo ilustram essa questão.

(sujeito 58, 5 anos) "Its legs are bending. It would be heavy".

(sujeito 115, 8 anos) "Porque as pernas tão dobradas, o que ele tá segurando é pesado.

Os informantes não fazem menção ao desconforto psicológico de carregar um objeto pesado, embora seja possível que eles reconheçam o malestar psicológico causado pelo esforço físico.

\section{Metáfora primária 5: ACEITAR É ENGOLIR}

A figura correspondente à MP5 consiste de dois Dunis: um está com um sorvete na mão e o outro está com um sorvete na boca.

Quanto aos sujeitos que obtiveram pontuação '0' (zero), ou seja, sujeitos que não deram respostas esperadas, algumas das suas justificativas para a escolha do Duni com o sorvete na mão giraram em torno de uma suposta atenção dispensada às desculpas do outro, como ilustram as respostas abaixo.

(sujeito 88, 9 anos) "He is probably listening carefully, the other is not".

(sujeito 146, 10 anos) "Porque parece que ele está ouvindo, ao invés de comer o sorvete".

Embora essas respostas sejam apropriadas e justifiquem adequadamente por que o boneco escolhido é o que vai aceitar as desculpas, elas receberam pontuação ' 0 ', porque não correspondiam à resposta esperada, relacionada ao entendimento da metáfora ACEITAR É ENGOLIR. Essas respostas indicam que o desenho, nesse item, não se prestou à função desejada, a de medir a compreensão da metáfora primária em questão.

\section{Metáfora primária 6: INTIMIDADE EMOCIONAL É PROXIMIDADE}

Além dos altos escores obtidos pelos sujeitos brasileiros e americanos nas duas tarefas utilizadas para avaliar a compreensão da MP6, também houve um alto índice de concordância na qualidade das respostas dos 
sujeitos, os quais justificaram suas escolhas com a proximidade física dos bonecos.

(sujeito 57, 5 anos) "They are next to each other"

(sujeito 172, 6 anos) "Porque tão mais juntinhos".

Tais respostas corroboram a idéia de que a correlação experienciada entre ser emocionalmente íntimo de uma pessoa e estar fisicamente perto dela é o que motiva a metáfora conceitual INTIMIDADE EMOCIONAL É PROXIMIDADE.

\section{Metáfora primária 7: IMPORTÂNCIA É TAMANHO}

Em relação à MP7, tanto crianças quanto adultos deram respostas não esperadas, em função de algum tipo de identificação. Algumas crianças escolheram o menor porque se identificaram com o Duni pequeno, e alguns adultos fizeram tal escolha porque identificaram seus filhos com a figura pequena, como revelam as respostas abaixo.

(sujeito 58, 5 anos) "Because it is little. My Dad says I am the most important thing". (sujeito 4, adulto) "The little one doesn't know much, like my little one".

Muitos sujeitos responderam adequadamente à pergunta pelo mesmo motivo que os sujeitos que não pontuaram nessa questão, por identificação. Nesse caso, crianças e adultos que obtiveram pontuação 1, que apontaram o maior como sendo o mais importante, identificaram o boneco maior com a figura paterna, ou materna, o que revela o quão relacionada está a interação pais e filhos com a conexão metafórica que se estabelece entre os domínios conceituais TAMANHO e IMPORTÂNCIA.

Outros participantes explicitaram, em suas respostas, a correlação entre o tamanho das pessoas e as imposições determinadas por seu tamanho e força na interação com outras pessoas. Os sujeitos percebem que o maior pode se destacar e exercer um domínio físico ou psicológico.

(sujeito 19, 10 anos) "It's bigger, easier to see. It probably wants to be like that, so be can stand up more".

(sujeito 82, adulto) "He could have more done, by intimidating or by lifting something".

(sujeito 186, adulto) "Ele está em mais destaque, pois é maior". 
Essas respostas reiteram a idéia de que a correlação experienciada entre o tamanho dos objetos ou pessoas e a dificuldade que isso representa na interação com eles propicia o mapeamento entre os domínios TAMANHO e IMPORTÂNCIA. Essa correlação é vivenciada diariamente pelas crianças na sua interação com pessoas maiores, particularmente com os pais, que podem lhes dominar pela força física.

\section{Metáfora primária 8: SIMPATIA É SUAVIDADE}

Na MP8, a maioria dos sujeitos entrevistados que optou pelo boneco forrado de veludo como sendo mais simpático deu como justificativa para tal escolha a maciez do boneco. Para esses participantes, parece explícita a associação entre a sensação prazerosa proporcionada pelo toque no objeto aveludado e a noção de 'simpatia'.

(sujeito 66, 9 anos) "Soft is another way to say really nice. And hard is another way to say really mean".

(sujeito 6, 5 anos) "Because he is soft, and soft means kind of love. If he is sick, he can have a blanket, which is soft".

(sujeito 53, 7 anos) "He is softer, he doesn't want to hurt others".

(sujeito 154, 8 anos) "Porque não arranha".

(sujeito 176, adulto) "Porque tá mais gostoso de tocar".

Respostas como as dos sujeitos 6 e 53 reforçam a idéia central da Teoria das Metáforas Primárias de que existem certas cenas e eventos básicos que ocorrem na nossa experiência diária e que resultam no entendimento subjetivo desses eventos. O sujeito 53 explica que o boneco, por ser macio, não quer machucar ninguém, o que geraria uma reação negativa, tanto física quanto psicológica. O sujeito 6 associa a maciez do cobertor com o conforto psicológico ("um tipo de amor") proporcionado pelo seu uso. A cena primária corresponde, nesse caso, à correlação entre a sensação física agradável gerada pelo toque no objeto macio e uma avaliação psicológica positiva, correspondente à sensação prazerosa.

A resposta do sujeito 94, que gerou uma pontuação '0', é esclarecedora porque fornece uma explicação para a diferença no resultado dos participantes mais velhos (a partir dos 7 anos de idade) nas tarefas verbal e não-verbal.

(sujeito 94, adulto) "If I use the words, I would say softer is kinder, but not with the pictures". 
Conforme já foi mencionado, o melhor desempenho de crianças a partir dos 7 anos de idade e adultos na tarefa verbal em relação à tarefa nãoverbal está intimamente ligado ao grau de convencionalidade de certas expressões metafóricas. Ou seja, algumas expressões são tão convencionais para os sujeitos, que eles associam lingüisticamente dois conceitos com naturalidade, mas estranham a associação pictórica desses mesmos conceitos, conforme ilustra a verbalização acima.

\section{Conclusão}

A partir de uma tarefa de compreensão verbal e de uma tarefa de compreensão não-verbal, investigamos a compreensão infantil de oito metáforas primárias, tentando responder, basicamente, a duas questões. A primeira questão está relacionada ao padrão evolutivo verificado na compreensão das diversas metáforas primárias. Os dados para a investigação das mudanças decorrentes do desenvolvimento foram coletados através de entrevistas com sujeitos monolíngües, de 3 a 10 anos de idade e adultos, falantes de inglês ou de português.

As análises dos dados sugerem um padrão de desenvolvimento de três fases. Na primeira fase, aos 3-4 anos de idade, já há algum entendimento das metáforas primárias e, nessa fase, a compreensão é maior quando o modo de veicular as metáforas é pictórico (aproximadamente $57 \%$ de respostas esperadas), ao invés de verbal (aproximadamente $44 \%$ de respostas esperadas). Aos 5-6 anos de idade, o entendimento das metáforas primárias é significativamente maior do que na faixa etária anterior, tanto na forma verbal (70\% de respostas esperadas) quanto na forma não-verbal (mais de $75 \%$ de respostas esperadas), mas a apresentação das metáforas em forma de desenhos ainda faz com que essas sejam mais facilmente compreendidas. A partir dos 7-8 anos de idade, a habilidade para compreender metáforas primárias já está plenamente adquirida (mais de $80 \%$ de respostas esperadas), e já não se percebem diferenças significativas com o desempenho dos adultos. A realização verbal - provavelmente em função da freqüência com que as metáforas conceituais são utilizadas lingüisticamente - passa, dessa faixa etária em diante, a ser a forma mais fácil de compreensão.

A segunda questão diz respeito às similaridades e diferenças verificadas na compreensão de metáforas primárias por sujeitos falantes de portu- 
guês e de inglês. A análise dos dados mostrou um alto grau de similaridade entre as duas línguas. Conforme os dados obtidos, a língua falada pela criança pouco afeta a compreensão de metáforas primárias. A expectativa de que a compreensão infantil das oito metáforas primárias analisadas fosse similar para os sujeitos falantes de português e inglês está intimamente ligada ao caráter universal das metáforas primárias.

Alguns estudos interlingüísticos (Yu, 1998; Lima et al., 2001; Kövecses, 2002 e 2005; Ozçaliskan, 2002), comparando metáforas encontradas em chinês, português, húngaro e turco com dados do inglês, apontam evidências lingüísticas para a universalidade de certos mapeamentos metafóricos. A idéia é que a fisiologia humana e as experiências corpóreas são fatores que propiciam mapeamentos metafóricos potencialmente universais.

Por outro lado, as experiências corpóreas dependem de interações com ambientes físicos, sociais e culturais específicos. Conseqüentemente, é de se esperar que existam variações cognitivas entre culturas e línguas (Yu, 1998). Gibbs (1999), nesse sentido, afirma que as metáforas baseadas em experiências corpóreas surgem não só do corpo e de suas representações na mente das pessoas, mas de interações corpóreas que são amplamente definidas pela cultura.

Nesta pesquisa foram encontradas poucas diferenças interlingüísticas. Esse resultado deve estar relacionado ao tipo de metáforas aqui adotadas, as metáforas primárias. Talvez esse resultado também esteja relacionado ao fato de que os participantes desta pesquisa, crianças de nível sociocultural médio, gaúchas e californianas, que vivem em um ambiente urbano, tenham práticas culturais muito semelhantes.

Os resultados encontrados foram consistentes nas duas línguas, português e inglês, nos diversos domínios conceituais, e corroboram a proposta de Grady (1997) de que as metáforas A FELICIDADE É PARA CIMA, INTENSIDADE DE EMOÇÃO É CALOR, BOM É CLARO, DIFICULDADE É PESO, INTIMIDADE EMOCIONAL É PROXIMIDADE, IMPORTÂNCIA É TAMANHO, SIMPATIA É SUAVIDADE são primárias, oriundas de correlações entre dimensões distintas - físicas e psicológicas experienciadas. A análise dos dados relativos à compreensão da metáfora conceitual ACEITAR É ENGOLIR, por outro lado, não permite que se façam afirmações conclusivas a respeito do seu status. 
Em suma, os dados indicam que o entendimento das metáforas é uma capacidade lingüística e conceitual que emerge cedo na infância e está vinculada ao entendimento infantil dos mapeamentos metafóricos envolvidos.

Recebido em março de 2005

Aprovado em março de 2007

E-mail: maitysiqueira@hotmail.com

\section{REFERÊNCIAS BIBLIOGRÁFICAS}

BILlow, R. M. 1975. A cognitive developmental study of metaphor comprehension. Developmental Psychology, 11 (4): 415-423.

.1981. Observing spontaneous metaphor in children. Journal of Experimental Child Psychology, 31: 430-445.

Cacciari, Cristina e Patricia Tabossi. 1988. The comprehension of idioms. Journal of Memory and Language, 27: 668-683.

Cameron, L. 1997. Discourse context and the development of metaphor in children. In: THOMPSON, L. (Ed.). Children talking: the development of pragmatic competence. Clevedon: Multilíngual Matters Ltd: 49-64.

Caramelli, Nicoletta e Angela Montanari. 1995. Animal terms in children's metaphors. Cognitive Science Research, 53: 3-26.

Dent, C. H. 1987. Developmental studies of perception and metaphor: the twain shall meet. Metaphor and Symbolic Activity, 2 (1): 53-71.

Dowker, A., G. Krasowicz, G. Pinto, A. Roazzi e A. Smith. 1998. Phonological and semantic devices in very young children's poems: A cross-cultural study. Cabiers de psychologie cognitive/ Current psychology of cognition, 17 (2): 389-416.

Elbers, L. 1988. New names from old words: related aspects of children's metaphors and word compounds. Journal of child language, 15 (3): 591617.

Epstein, R. L., P. J. Gamblin. 1994. Young children's comprehension of simple and complex metaphors presented in pictures and words. Metaphor and Symbolic Activity, 9 (3): 179-191.

GARDNER, H. 1974. Metaphor and modalities: how children project polar adjectives onto diverse domains. Child Development, 45: 84-91. 
GibBs, Jr. Raymond W. 1994. The poetics of mind: figurative thought, language and understanding. New York: Cambridge University Press. . 1996. Why many concepts are metaphorical. Cognition, 61: 309319.

. 1999. Taking metaphor out of our heads and putting it into the cultural world. In: GibBs, R.; STEEN, G. Metaphor in Cognitive Linguistics. Amsterdam: John Benjamins.

GRADY, Joseph. 1997. Foundations of meaning: primary metaphors and primary scenes. Tese (Doutorado em Lingüística) - University of California, Berkeley.

Johnson, Christopher. 1999. Constructional grounding: the role of interpretational overlap in lexical and constructional acquisition. Tese (Doutorado em Lingüística) - University of California, Berkeley.

Kövecses, Zoltan. 2002. Metaphor: a practical introduction. New York: Oxford University Press. 2005. Metaphor in culture: universality and variation. New York: Cambridge University Press.

Laganaro, Marina. 1997. Production et compréension des metaphores chez l'enfant: de la similitud a la metaphore. Archives de Psychologie, 65: 141-163.

LAKOFF, George e Mark JOHNSON. 1980. Metaphors we live by. Chicago: University of Chicago Press.

Levorato, Maria Chiara. 1993. The acquisition of idioms and the development of figurative competence. In: CACCIARI, Cristina; TABOsSI, Patricia. (Eds.), Idioms: processing, structure, and interpretation. Hissdale: Lawrence Erlbaum Associate Publishers: 101-128.

Levorato, Maria Chiara e Cristina Cacciari. 1995. The effects of different tasks on the comprehension and production of idioms in children. Journal of Experimental Child Psychology, 60: 261-283.

Lima, Paula C. L., Raymond W Gibbs, Jr. e Edson Françoso. 2001. Emergência e natureza da metáfora primária - desejar é ter fome. Cadernos de Estudos Lingüísticos, 40: 107-140, jan./jun.

Marschark, Mark e Lynn Nall. 1985. Metaphoric competence in cognitive and language development. Advances in Child Development and Behavior. 19: 49-78.

Moore, B. 1988. A young child's use of a physical-psychological metaphor. Metaphor and Symbolic Activity, 3 (4): 223-232. 
Ozçaliskan, Seyda. 2002. Metaphors we move by: a crosslinguisticdevelopmental analysis of metaphorical motion events in English and Turkish. Tese (Doutorado em Psicologia) - University of California, Berkeley.

Pearson, B. Z. 1990. The comprehension of metaphor by preschool children. Journal of child language, 17 (1): 185-203.

Semino, E., J. Heywood e M. Short, Methodological problems in the analysis of metaphors in a corpus of conversations about cancer. 2004. Journal of Pragmatics, 36: 1271-1294.

Siqueira, Maity. 2001. O papel do corpo na conceitualização das emoções: Compreensão e produção de metáforas. Letras de Hoje, 125: 641-69

Siqueira, Maity e Francisco Settineri. 2003. A aquisição da metáfora: Um estudo exploratório. Letras de Hoje, 132: 197-204.

Steen, Gerard e Raymond Gibbs. 1999. In: Gibbs, R.; Steen, G. Metaphor in Cognitive Linguistics. Amsterdam: John Benjamins.

Yu, Ning. 1998. The Contemporary Theory of Metaphor. Philadelphia: John Benjamins,

Vosniadou, Stella. 1987. Children and metaphors. Child development, 58 : 870-885.

Winner, E., W. Wapner, M. Cicone e H. Gardner. 1979. Measures of metaphor. New Directions for Child Development, 6: 67-75.

\section{ANEXO}

1) Metáfora primária: A FELICIDADE É PARA CIMA

MP: 'A Lúcia está se sentindo para cima depois de encontrar o Tom'.

AL: 'A Lúcia está feliz depois de encontrar o Tom'.

Perguntas: Como será que a Lúcia está se sentindo? Será que o Tom deu boas ou más notícias para ela?

2) Metáfora primária: INTENSIDADE DE EMOÇÃO É CALOR MP: 'O Duda está fervendo'.

AL: 'O Duda está furioso'.

Perguntas: O que será que aconteceu? Como ele está se sentindo?

3) Metáfora primária: BOM É CLARO

MP: A Pati tem uma idéia brilhante! 
AL: A Pati tem uma idéia excelente!

Perguntas: Tu achas que isso é bom ou não? Adivinha o que aconteceu depois de ela ter contado isso para os outros.

4) Metáfora primária: DIFICULDADE É PESO

MP: 'A Ana tem um jogo pesado hoje!'

AL: 'A Ana tem um jogo difícil hoje!'

Perguntas: Tu achas que é fácil ou difícil p/ ela? Como será que ela está se sentindo?

5) Metáfora primária: ACEITAR É ENGOLIR

MP: 'A mãe do Chico não engoliu as desculpas que ele deu para ela'.

AL: 'A mãe do Chico não aceitou as desculpas que ele deu para ela'.

Perguntas: Tu achas que isso é ruim ou bom? O que será que ela vai fazer?

6) Metáfora primária: INTIMIDADE EMOCIONAL É PROXIMIDADE MP: 'Pedro e Kátia são próximos'.

AL: 'Pedro e Kátia são íntimos'.

Perguntas: Será que eles gostam um do outro? Por quê?

7) Metáfora primária: IMPORTÂNCIA É TAMANHO

MP: 'Hoje é um grande dia para a Silvia'.

AL: 'Hoje é um dia importante para a Silvia'.

Perguntas: O que tu achas que vai acontecer? Como tu achas que ela está se sentido?

8) Metáfora primária: SIMPATIA É SUAVIDADE

MP: 'A Susi trata os gatos com suavidade'.

AL: 'A Susi trata os gatos com gentileza'.

Perguntas: A Susi gosta de gatos? Como ela trata os gatos? 